\title{
Uma abordagem sobre o papel da mulher na cadeia produtiva do café no Município da Barra do Choça, Bahia
}

\author{
Paulo Roberto Pinto Santos \\ Universidade Estadual do Sudoeste da Bahia (UESB) Campus de \\ Vitória da Conquista \\ Ariana Lisboa Meira \\ Universidade Estadual do Sudoeste da Bahia (UESB) Campus de \\ Vitória da Conquista \\ Sandra Elizabeth Souza \\ Universidade Estadual do Sudoeste da Bahia (UESB) Campus de \\ Vitória da Conquista
}

\begin{abstract}
Resumo
O Município da Barra do Choça, distante $27 \mathrm{~km}$ de Vitória da Conquista, é destaque na produção de café na região do Planalto da Conquista desde a implantação da cultura. Este trabalho teve como objetivo estudar o papel da mulher inserida em diversos setores da cadeia produtiva do café no Município da Barra do Choça na Bahia, visando à satisfação com a atividade que exerce, a relação trabalho/família, sua autoestima e a definição sobre quem é esta mulher. Este estudo foi realizado por meio da aplicação de questionário, abrangendo dados pessoais, atuação na cadeia produtiva do café, relação trabalho/família, trajetória do trabalho fora de casa, realização profissional, lazer nos finais de semana, mulher na cafeicultura, e quem é a entrevistada. Foram entrevistadas 25 mulheres, entre elas 24 na zona rural, sendo Assentamento Mocambo, Ingazeira e Santo Antônio II (três), Pau Brasil e Santo Antônio I (duas), Boa Vista e Coqueiro (uma), Sossego (nove) e no próprio Município da Barra do Choça (uma). Conclui-se que a participação da mulher dentro do setor cafeeiro no Município da Barra do Choça está em crescimento e que estas mulheres estão satisfeitas com a atividade que exercem, pois conseguem conciliar trabalho e família, e possuem elevada autoestima.
\end{abstract}

Palavras-chave: Cadeia cafeeira. Mulheres no café. Participação feminina.

\section{An approach on the role of women in the coffee production chain in the municipality of Barra do Choça, Bahia}

\footnotetext{
Abstract

The city of Barra do Choça, $27 \mathrm{~km}$ from Vitoria da Conquista, always stood out in coffee production in the Planalto da Conquista of achievement since the implementation of culture. This work aimed to study the role of the inserted women in various sectors of the
} 
coffee production chain in Barra do Choça of the city in Bahia, aimed at satisfaction with the activity that carries the work/ family relationship and self-esteem, your self-esteem and the definition of who this woman is. This study was conducted through a questionnaire, including personal data, operations in the coffee production chain, relationship work/family, work trajectory away from home, job satisfaction, leisure on weekends woman in coffee growing, and who is name of the interviewee. They interviewed 25 women in different sector of production chain of coffee, between them, 24 in rural area, wich is Assentamento Mocambo, Ingazeira e Santo Antonio II (three), Pau Brasil e Santo Antonio I (two), Boa Vista e Coqueiro (one), Sossego (nine) e in urban region of Barra do Choça (one). And concluded that the participation of women in the coffee sector in the city of Barra do Choça, is growing and that these women are satisfied with the activity engaged because they can reconcile work and family, and have high self-esteem.

Keywords: Coffee chain. Women in coffee. Participation of women.

\section{Un enfoque sobre el papel de la mujer en la cadena productiva del café en el municipio de la Barra del Choza, Bahía}

\section{Resumen}

El municipio de Barra do Choza, distante 27 km de Vitória da Conquista, es destaque en la producción de café en la región del Planalto da Conquista desde la implantación de la cultura. Este trabajo tuvo como objetivo estudiar el papel de la mujer insertada en diversos sectores de la cadena productiva del café en el municipio de Barra do Choza en Bahía, buscando la satisfacción con la actividad que ejerce la relación trabajo / familia, su autoestima y la definición sobre quién es esta mujer. Este estudio fue realizado a través de la aplicación de cuestionario, abarcando datos personales, actuación en la cadena productiva del café, relación trabajo / familia, trayectoria del trabajo fuera de casa, realización profesional, ocio en los fines de semana, mujer en la cafeicultura, y quién es nombre de la entrevistada. Se entrevistó a 25 mujeres, entre ellas 24 en la zona rural, siendo Asentamiento Mocambo, Ingazeira y Santo Antônio II (tres), Pau Brasil y Santo Antônio I (dos), Boa Vista y Coqueiro (una), Sossego (nueve) y en el propio Municipio de Barra do Choza (una). Se concluye que la participación de la mujer dentro del sector cafetero en el municipio de Barra do Choza, está en crecimiento y que estas mujeres están satisfechas con la actividad que ejercen, pues logran conciliar trabajo y familia, y poseen elevada autoestima.

Palabras clave: Cadena cafetera. Mujeres en el café. Participación femenina.

\section{INTRODUÇÃO}

O Município da Barra do Choça, situado na região cafeeira do Planalto da Conquista, é o maior produtor de café arábica (Coffea arabica) do norte/nordeste brasileiro, com uma produção média que varia de 250 e 300 mil sacas de café de 60 $\mathrm{kg} / \mathrm{ano}$, em $40 \mathrm{mil}$ ha plantados. E esta cultura tem contribuído para o fortalecimento da economia regional. Apenas no Município de Barra do Choça, que tem aproximadamente 1600 propriedades rurais, sendo que, deste total, 60\% são da agricultura familiar e $80 \%$ da renda é oriunda da cafeicultura (EBDA - EMPRESA BAIANA DE DESENVOLVIMENTO AGRÍCOLA, 2012). Esses agricultores familiares estão organizados em associações e cooperativas, que vem sendo incentivadas desde os anos 1990 pela Prefeitura e Secretaria Municipal de Agricultura da Barra do Choça (PEREIRA et al., 2011). 
A partir da década de 1970, com a implantação da lavoura cafeeira, o Município da Barra do Choça vem apresentando bons resultados em relação à expansão da cultura do café, pois favorecem aos cafeicultores melhores condições de vida, tais como, saúde, educação, habitação e melhoria da autoestima.

No campo da produção, a mulher tem sido precursora dentro da unidade familiar, assumindo os desafios de começar algo novo, ao mesmo tempo em que desafia a agricultura convencional ao colocar em prática saberes adquiridos em outras gerações, questionando as formas de produzir e demonstrando descontentamento nos casos em que a lucratividade imediata sobrepõe o bemestar da família (LOVATTO et al., 2010).

Atualmente, as mulheres buscam a sua realização pessoal e profissional, pois atuam nas unidades produtivas familiares, combinando atividades agrícolas e não agrícolas, porque há necessidade de diversificação das fontes de renda familiar, da busca por atividades que permitam construir maiores níveis de autonomia frente às relações antagônicas impostas pelo mercado dos produtos agrícolas.

Segundo Jonathan (2005) no Brasil é relevante o número de empresas lideradas por mulheres que buscam se incluir e permanecer no mercado de trabalho, assim como criar empregos e contribuir para que o País se desenvolva socioeconomicamente. Para Schemer e Carvalho (2010) na última década muitos pesquisadores se interessaram pelo estudo das mulheres que trabalham por conta própria. Dessa maneira, são recentes os estudos sobre mulheres empreendedoras.

Os grupos de mulheres estão organizados em associações, cooperativas ou aquelas ainda na informalidade elevam sua autoestima e rompem as barreiras do preconceito ao conquistarem os espaços econômicos de forma conjunta (MORAIS et al., 2011).

A Aliança Internacional das Mulheres do Café - IWCA constitui no fortalecimento de uma rede de contatos, na execução de cursos de treinamento e na incorporação das mulheres na cadeia de abastecimento. As mulheres que fazem parte desta Aliança produzem café de qualidade, entretanto há necessidade de aprender a comercializá-lo. Segundo Neto (2015), há realização de treinamento, capacitação e desenvolvimento das lideranças, preparando-as para que façam negócios para beneficiarem suas famílias.

Em muitos casos, é a mulher a responsável pela introdução das novas práticas de produção, na medida em que testa formas e preparados nos cultivos, dedica-se ao artesanato, à culinária, aos agrupamentos sociais, recuperando, desta forma, a cooperação em todas as esferas produtivas. Ela aparece como o centro de formação das articulações no meio rural, conectando, às vezes, por meio da religiosidade, a família e a comunidade, movimentando a vizinhança para uma mudança de hábitos (LOVATTO et al., 2010). Dentro desse contexto, o objetivo deste estudo foi analisar o papel da mulher inserida em diversos setores da cadeia produtiva do café no Município da Barra do Choça na Bahia, visando à satisfação com a atividade que exerce, a relação trabalho/família e sua autoestima.

\section{PARTICIPAÇÃO DAS MULHERES NO COOPERATIVISMO}

O movimento cooperativista iniciou-se em 1844, na Inglaterra, em meio à Revolução Industrial, com o objetivo de unir forças dos trabalhadores para obter 
maiores e melhores resultados do trabalho de forma organizada. Com rápida expansão, o cooperativismo expandiu-se pela Europa e pelo mundo e, em 1881, já existiam mil cooperativas de consumo, com aproximadamente 550.000 associados (DALLER, 2009).

O Brasil é filiado à Aliança Cooperativa Internacional - $\mathrm{ACl}$ desde 1989 (DALLER, 2009), e tem a maior presença de mulheres no cooperativismo popular, que visa à geração de trabalho e renda, contribuindo igualitariamente para a composição do capital necessário à formação da sociedade cooperativa, sendo a força de trabalho o principal capital de que dispõem. E, segundo a Organização das Cooperativas do Brasil - OCB, as mulheres representavam 52\% dos 296 empregados das cooperativas brasileiras (CIRILO, 2013).

Estas mulheres estão na produção de vestuário, na alimentação e no artesanato, principalmente a partir de materiais típicos de sua região, como também em propriedades rurais (NAZZARI et al., 2007). E, segundo Morais et al (2011), os grupos de mulheres estão organizados em associações, cooperativas ou aquelas ainda na informalidade elevam sua autoestima e rompem as barreiras do preconceito ao conquistar os espaços econômicos de forma conjunta.

\section{Gênero na agricultura familiar}

É possível observar mudanças no comportamento das mulheres para competir em igualdade com os homens (DAMASCENO, 2010). Essa mudança foi aumentada com a participação das mulheres no mercado de trabalho, que teve início em 1975, quando a ONU reconheceu a questão da mulher como um problema social, declarando como Ano Internacional das Mulheres. Nas últimas décadas do século XX, o País passou por transformações profundas no âmbito demográfico, cultural e social, influenciando diretamente no trabalho feminino (BRUSCHINI et al., 2010).

Hoje, as mulheres buscam a sua realização pessoal e profissional, pois atuam nas unidades produtivas familiares, combinando atividades agrícolas e não agrícolas, porque há necessidade de diversificação das fontes de renda familiar, da busca por atividades que permitam construir maiores níveis de autonomia frente às relações antagônicas impostas pelo mercado dos produtos agrícolas.

A agricultura familiar brasileira é responsável por aproximadamente $38 \%$ do valor bruto da produção de alimentos do País, o que representa em torno de $10 \%$ do Produto Interno Bruto - PIB agrícola, corresponde a $85 \%$ dos estabelecimentos agropecuários e responde por quase $77 \%$ dos postos de trabalho na agricultura (CASTILHO E SCHNEIDER, 2010). Entretanto, segundo os mesmos autores, pouco se conhece da parcela destas proporções no que se refere à contribuição das mulheres nas unidades familiares de produção .

\section{MULHERES NOS MOVIMENTOS SOCIAIS DO BRASIL}

No Brasil, os movimentos sociais de mulheres começaram a ganhar destaque na década de 1980, articulado à luta popular, ao direito à terra e aos títulos dos lotes no campo (PEDRO, 2005). No entanto, o novo no movimento das mulheres referiase aos direitos sociais modernos, que lutavam pela igualdade e liberdade, em 
termos das relações de gênero (GOHN, 2003). Dessa forma, a libertação das mulheres inicia a partir da criação e disseminação de movimentos feministas (SANTOS, 2009).

A luta das mulheres no movimento feminista é um bom exemplo para esclarecer o campo de ação dos movimentos, não dominado a nenhuma ordem ou escala de "luta" principal ou secundária, o que é interessante para nos alertar sobre a concepção ampliada de movimento social, onde nem tudo que muda na sociedade é sinônimo ou resultado da ação deste movimento, pois este é uma das formas possíveis de mudança e transformação social (GOHN, 2003).

E essa transformação social requeria demandas dos mais diversos espaços, sendo três os tipos de movimentos de mulheres rurais: Movimentos Autônomos, Movimento Sindical e o Movimento das Mulheres ligado ao Movimento dos Trabalhadores Rurais Sem Terra - MST. A partir desses três movimentos rurais, inicia-se a discussão sobre as condições das mulheres no campo e mais do que isso, questiona-se as condições das mulheres dentro dos próprios movimentos sociais (SANTOS, 2009).

A expropriação da terra, do trabalho, da renda rural, a falta de condições de sobrevivência no campo e na cidade parece ser a motivação original que leva muitas mulheres a participarem das reuniões para a organização das ocupações. Dessa forma, nas décadas de 1980 e 1990, as mulheres se inserem nos movimentos sindicais, nos partidos políticos, nos movimentos sociais na defesa da afirmação "do outro" e de "outra mulher", na ressignificação da mulher como sujeito político, na luta por direitos e igualdade de oportunidades (SANTOS, 2009).

Para Gohn (2007), essa atuação das mulheres não se materializa em reconhecimento da importância da participação da mulher na construção do Movimento por parte de seus dirigentes, havendo uma invisibilidade na atuação das mulheres.

\section{METODOLOGIA}

\subsection{Local e período de coleta de dados}

O Município da Barra do Choça está localizado entre as coordenadas geográficas $14^{\circ} 51^{\prime} 52^{\prime \prime}$ de latitude sul e $40^{\circ} 34^{\prime} 44^{\prime \prime}$ de longitude oeste. Possui 778 $\mathrm{km}^{2}$ de área total, de clima tropical semiúmido, a 840m de altitude, banhada pelos rios Catolé, Gaviãozinho, Choça, Monos e Água Fria (PEREIRA et al., 2011).

Este trabalho foi realizado na zona rural e no próprio Município da Barra do Choça. Para execução deste trabalho, realizaram-se sete visitas, nos dias 12 de dezembro de 2012; 14, 25 e 30 de janeiro de 2013; 04, 14 e 26 de fevereiro de 2013.

\subsection{Mulheres entrevistadas}

Foram entrevistadas 25 mulheres de diferentes setores dentro da cadeia produtiva do café, dentre elas, no Assentamento Mocambo, Ingazeira e Santo Antônio II (três), Pau Brasil e Santo Antônio I (duas), Boa Vista e Coqueiro (uma), Sossego (nove) e no próprio Município da Barra do Choça (uma), sendo cinco de movimentos sociais, 19 agricultoras familiares e uma média agricultora. 
A escolha dessas mulheres foi por meio de indicações de docente, do presidente da Cooperativa Mista Agropecuária dos Pequenos Agricultores do Sudoeste da Bahia Ltda. - COOPASUB, dos dirigentes do Movimento dos Trabalhadores Rurais Sem Terra - MST e Movimento dos Pequenos Agricultores MPA de Vitória da Conquista, e de uma representante da União das Cooperativas da Agricultura Familiar no Estado da Bahia - UNICAFES do Município da Barra do Choça.

\subsection{Procedimento da entrevista}

Após a escolha das entrevistadas, foi realizado o contato por meio de ligações, foi explicado resumidamente o motivo e o objetivo da pesquisa, e, em caso de aceite, agendou-se o dia da entrevista.

Antes do início da aplicação dos questionários, foi esclarecida de forma mais detalhada o objetivo do questionário, como seria realizada a pesquisa e a sua importância tanto para as entrevistadas quanto para o meio acadêmico, e assumindo o compromisso de esclarecer as dúvidas que poderiam surgir durante a entrevista, mediante a assinatura do termo de compromisso.

Houve também o termo de consentimento para participação, que as entrevistadas assinaram, aceitando participar voluntariamente, livre de qualquer forma de remuneração e que os dados da pesquisa seriam utilizados somente para fins acadêmicos e científicos.

Logo após, iniciou-se a entrevista com a aplicação do questionário. Este questionário foi adaptado de Gomes (2010) e Cruz (2006), composto por dados pessoais, atuação na cadeia produtiva do café, relação trabalho/família, trajetória do trabalho fora de casa, realização pessoal, lazer e fins de semana, mulher na cafeicultura e o nome da entrevistada.

\subsection{Análise de dados}

Após a aplicação dos questionários, foi realizada a tabulação e análise de dados de forma quantitativa e qualitativa.

\section{RESULTADOS E DISCUSSÃO}

Ao iniciar a entrevista, muitas mulheres ficaram inseguras, pois se escutou inúmeras vezes “... será que eu vou saber responder?”, “... e se eu responder errado?” ou “... será que eu sei responder?”, e “...ele (esposo), não vai ficar aqui?”. E poucas se sentiram à vontade no início da entrevista. Entretanto, no decorrer da entrevista, percebeu-se que as inseguranças haviam desaparecido. Isso porque, as entrevistadas ficaram à vontade para falar sobre sua vida e, algumas vezes, respondiam além das perguntas, demandando maior tempo para conclusão do questionário. Além das inseguranças, também foram observados outros comportamentos, como medo, pressa (pois tinha que fazer o almoço), angústia, felicidade, satisfação e superação.

Dessa maneira, apesar do questionário ter sido extenso, por fim todas se sentiram prestigiadas e foi possível obter informações sobre o conhecimento, sentimento, desejos, sonhos, o que fizeram, e o que fazem, o que pretendem fazer. 


\subsection{Dados pessoais}

O número de mulheres entrevistadas que se enquadram em movimentos sociais variou em relação à idade, o número de filhos e grau de escolaridade. A idade foi de 30 anos a mais de 50 anos, a quantidade de filhos foi de um a seis e o grau de escolaridade foi do $1^{\circ}$ ano ao $5^{\circ}$ ano incompleto até cursando técnico em agropecuária. O mesmo ocorreu em relação às agricultoras familiares, pois a idade variou de 20 anos a acima de 50 anos, o número de filhos oscilou de zero a nove e, em relação ao grau de escolaridade, entre $1^{\circ}$ ano ao superior completo (Tabela 1 ).

\section{Tabela 1. Número de mulheres, idade, quantidade de filhos e grau de escolaridade das entrevistadas no Município da Barra do Choça, no período de dezembro de} 2012 a fevereiro de 2013

\begin{tabular}{|c|c|c|c|}
\hline Número de mulheres & Idade & Número de filhos & Grau de escolaridade \\
\hline \multicolumn{4}{|c|}{ Movimentos Sociais } \\
\hline 1 & Entre 31 a 36 & 1 & Cursando Técnico em Agropecuária \\
\hline 2 & Acima de 50 & 3 & $1^{\circ}$ ao $5^{\circ}$ ano incompleto \\
\hline 3 & Acima de 50 & 3 & $1^{\circ}$ ao $5^{\circ}$ ano incompleto \\
\hline 4 & Acima de 50 & 6 & $1^{\circ}$ ao $9^{\circ}$ ano completo \\
\hline 5 & Acima de 50 & 5 & $5^{\circ}$ ao $9^{\circ}$ ano incompleto \\
\hline \multicolumn{4}{|c|}{ Agricultoras familiares } \\
\hline 1 & Entre 41 a 45 & 3 & $1^{\circ}$ ao $5^{\circ}$ ano incompleto \\
\hline 2 & Entre 46 a 50 & 3 & $1^{\circ}$ ao $5^{\circ}$ ano incompleto \\
\hline 3 & Acima de 50 & 5 & $1^{\circ}$ ao $5^{\circ}$ ano incompleto \\
\hline 4 & Acima de 50 & 4 & $6^{\circ}$ ao $9^{\circ}$ ano completo \\
\hline 5 & Acima de 50 & 2 & $1^{\circ}$ ao $5^{\circ}$ ano incompleto \\
\hline 6 & Acima de 50 & 4 & $1^{\circ}$ ao $5^{\circ}$ ano completo \\
\hline 7 & Entre 46 a 50 & 3 & $2^{\circ}$ grau completo \\
\hline 8 & Entre 20 a 30 & - & Superior incompleto \\
\hline 9 & Acima de 50 & 5 & $1^{\circ}$ ao $5^{\circ}$ ano incompleto \\
\hline 10 & Entre 36 a 40 & 3 & $6^{\circ}$ ao $9^{\circ}$ ano completo \\
\hline 11 & Entre 31 a 35 & 4 & $1^{\circ}$ ao $5^{\circ}$ ano completo \\
\hline 12 & Acima de 50 & - & Superior incompleto \\
\hline 13 & Entre 46 a 50 & 2 & $6^{\circ}$ ao $9^{\circ}$ ano completo \\
\hline 14 & Acima de 50 & 9 & Apenas lê e escreve \\
\hline 15 & Entre 46 a 50 & 4 & $6^{\circ}$ ao $9^{\circ}$ ano incompleto \\
\hline 16 & Entre 20 a 30 & - & Superior completo \\
\hline 17 & Entre 36 a 40 & 2 & $1^{\circ}$ ao $5^{\circ}$ ano completo \\
\hline 18 & Entre 41 a 45 & 2 & $1^{\circ}$ ao $5^{\circ}$ ano incompleto \\
\hline 19 & Entre 41 a 45 & 2 & Superior incompleto \\
\hline \multicolumn{4}{|c|}{ Média agricultora } \\
\hline 1 & Acima de 50 & 3 & $1^{\circ}$ grau completo \\
\hline
\end{tabular}

Fonte: elaborado pela autora.

Dentre as entrevistadas, somente três não tinham filhos, para as demais, a quantidade de filhos variou de um a nove. Para o grau de escolaridade, o mínimo foi apenas ler e escrever, sendo que três entrevistadas estão cursando ensino superior em Serviço Social e Pedagogia, ambas a distância e, dentre elas, uma é pedagoga e atualmente está fazendo Engenharia Agronômica na Universidade Estadual do Sudoeste - Uesb e outra concluiu licenciatura em Biologia pela mesma instituição.

As entrevistadas com mais idade, apesar de não terem estudado, seus filhos e netos estão estudando e muitos ou são graduados ou estão se graduando em 
instituições a distancia ou presencial. Alguns filhos (as) e netos (as) estudam na Uesb, pois tem transporte disponibilizado pela prefeitura do município, possibilitando acesso ao ensino superior. $E$ as entrevistadas que, depois de terem criado os filhos, voltaram a estudar e, para terem companhia, levam o esposo junto. Dessa maneira, ambos sentem-se entusiasmados com os estudos.

Em geral, pode ser observado que houve um aumento do nível de escolaridade e a redução da natalidade, corroborando Lombardi (2009), ao mencionar o aumento do nível de escolaridade das mulheres rurais. Em 1993, apenas 3,5\% tinham estudado, no mínimo, nove anos e, em 2006, este percentual aumentou 15,2\%, e Ribeiro (2015), ao relatar que mulheres com maior grau de escolaridade diminuem as taxas de natalidade e casam-se com idades mais avançadas.

\subsection{Atuação na cadeia produtiva do café}

A atuação das entrevistadas na cadeia produtiva do café foi diversificada, pois estas mulheres realizam mais de uma atividade, tanto relacionada com café quanto paralela à atividade cafeeira (Figura 1).

Figura 1. Atuação das entrevistadas inseridas dentro da cadeia produtiva do café no Município da Barra do Choça, no período de dezembro de 2012 a fevereiro de 2013

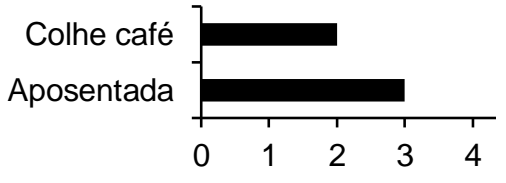

Figura $1 \mathrm{~A}$ - Movimento Sociais

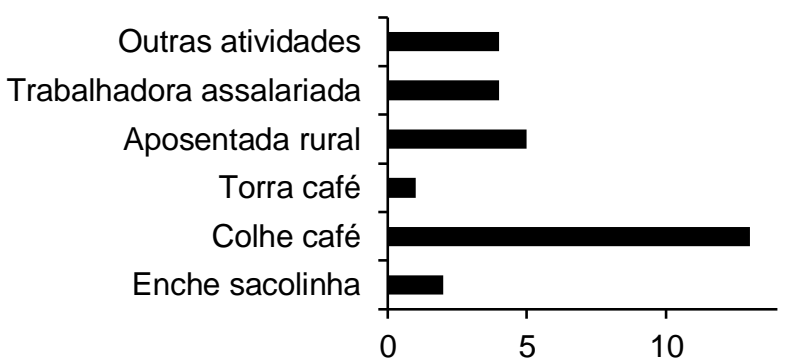

Figura 1B - Agricultoras Familiares

Na figura $1 \mathrm{~A}$, das cinco mulheres entrevistadas, três são aposentadas, e sempre trabalharam na roça, tanto com café quanto em outras culturas, como mandioca, feijão e milho. As demais entrevistadas colhem café da sua propriedade e de outras no período da colheita.

Em relação às agricultoras familiares (Figura $1 \mathrm{~B}$ ), elas realizam mais de uma atividade, sendo que 13 mulheres afirmaram colher café, destas, duas torram café em sua propriedade e cinco são aposentadas rurais, mas continuam trabalhando em suas propriedades. Três delas trabalham meio período como merendeira e uma é professora de escolas localizadas próximas a sua residência.

As outras atividades mencionadas por quatro entrevistadas foram: degustadora, técnica de Assistência Técnica de Extensão Rural - ATER, diretora comercial da Cooperativa Mista dos Pequenos Cafeicultores de Barra do Choça e Região Ltda - Cooperbac e meio período como Coordenadora Pedagógica. 
E a média produtora é empresária, pois a mesma diversifica sua produção fabricando balas de café com mel e de gengibre com mel e ainda, na época de São João, vende licor para a região e cidades próximas. E também gera emprego, pois tem três funcionárias. Essa empresária pretende permanecer no mercado de trabalho, corroborando Jonathan (2005). Desta forma, cria emprego e contribui para o desenvolvimento socioeconômico da região.

Dentre as pequenas produtoras, uma, que faz parte da administração da Cooperbc, é também coordenadora pedagógica de uma escola no Município da Barra do Choça. Outra, é filha de pequeno produtor e atualmente é técnica do ATER, participou de inúmeros cursos de degustação de café como organizadora, porém, a mesma afirmou que não tem certificado como degustadora de café: [...] quando estudava na Uesb, participei junto com o professor, de vários concursos de café, mais não tenho certificado". (AGRICULTORA - BARRA DO CHOÇA).

É possível observar que a presença das mulheres no mercado de trabalho atual é um fato indiscutível e irreversível, pois elas vêm buscando posições antes desempenhadas somente pelos homens. Para Cirolini e Noro (2008), elas empreendem e inovam seu próprio negócio, comprovando competências e habilidades na execução de suas atividades.

Esses resultados não diferem das mulheres que foram entrevistadas neste estudo, pois elas conseguiram conquistar os diversos setores da cadeia produtiva do café. No entanto, essas conquistas foram decorrentes de muitas discussões, conforme relatado por Santos (2009), e mudanças de comportamento (DAMASCENO, 2010).

Ao perguntar para as entrevistadas quanto tempo estão na atividade relacionada ao café, somente duas há de 10 anos, uma delas trabalha como técnica do ATER. A maioria trabalha com café entre 10 a 25 anos. E, dentre elas, nove desde a implantação da cultura no município.

O motivo pelo qual essas mulheres iniciaram atividades relacionadas ao café foram diversos. Um deles foi à implantação da cultura em 1975, pois era a cultura que melhor se adaptava à região, e outros motivos foram: "Porque gosto, pois é o único trabalho que aparece... Acabou o café, acabou o dinheiro". (AGRICULTORA SANTO ANTÔNIO II). Porque gosto... Para não ficar só em casa, põe muita besteira na cabeça. Trabalho de casa nunca acaba. Ir para roça é bom demais." (AGRICULTORA - SOSSEGO). Porque gosto, para ajudar. Gosto de ter dinheiro." (AGRICULTORA - BOA VISTA). Porque gosto da área... Pela Barra do Choça ter um histórico com a cafeicultura. E impregna (o café) na vida." (AGRICULTORA SOSSEGO).

As mulheres parecem trabalhar para buscar algo mais do que dinheiro. Para Damasceno (2010), elas querem recompensas não apenas financeiras, mas também "intrínsecas", tais como: satisfação, bem-estar e sensação de colaborar com algo importante, por exemplo, ter o próprio dinheiro para comprar o que desejam ou investir em algo novo, como é o caso da agricultora da região de Boa Vista, que torra o seu próprio café. E de outras produtoras, como foi mencionado pelas agricultoras da região de Boa Vista e do Pau Brasil, que cultivam o café separado do seu esposo, e o recurso que recebem é utilizado por elas mesmas. 
No entanto, apesar dessas mulheres atuarem participativamente no plantio, colheita, manejo, torra do café, a parte de comercialização é realizada pelos filhos ou esposo.

\subsection{Relação trabalho família}

Ao serem perguntadas sobre o que é trabalho para elas, algumas disseram que: “[...] trabalho é importante para a vida”, “[...] é o meio de sustento," “[...] porque tem que trabalhar", "[...] quem não trabalha fica doente”, "... é terapia” e outras foram mais abrangentes, como: "é honra. Tudo que vem fácil vai fácil. Tem que trabalhar mesmo". (AGRICULTORA - INGAZEIRA). "É tudo, porque sem trabalho a vida não continua". (AGRICULTORA - SOSSEGO). "Trabalhar é bom. É preciso trabalhar. É uma necessidade. Necessidade de buscar alguma coisa para sobrevivência. Sem trabalho ninguém sobrevive". (AGRICULTORA - SOSSEGO).

Sobre a renda mensal, variou entre um a dez salários mínimos e a participação delas no sustento da casa, para a maioria, foi de $50 \%$, ou seja, as despesas são divididas entre o casal. Isso evidencia a participação da mulher não somente como dona de casa, mas também que elas conseguem conciliar os serviços da casa com atividades da roça, e como foi mencionado anteriormente, participam em diversas atividades dentro da lavoura cafeeira. Exercem também outras atividades, como agente de saúde, merendeira, transporte escolar e professora.

Para elas, conciliar trabalho com a família, foi unanime ouvir que era complicado e tinha que se organizar. E, quando os filhos eram pequenos, elas iam trabalhar com o marido na roça ou comércio e eles ficavam com os familiares (sogra, cunhada, mãe, sobrinha), vizinha, dormindo em casa (pois não tinha com quem deixar os filhos), aos cuidados dos irmãos mais velhos, pagavam uma pessoa para cuidar deles, outras levavam para a roça, como: "[...] fazia umas caminhas de baixo do pé de café". (AGRICULTORA - SOSSEGO). "[...] ficavam dentro do balaio". (AGRICULTORA - ASSENTAMENTO MOCAMBO). "[...] colocava dentro da bacia". (AGRICULTORA - BOA VISTA - MPA). "[...] colocava os meninos na rede, a noite cuidava deles (dava banho, janta e colocava para dormir)" (AGRICULTORA ASSENTAMENTO MOCAMBO).

Em relação ao primeiro trabalho, dezessete das entrevistadas foram para a roça com os pais quando crianças, porém no sentido de acompanhá-los e não como trabalho infantil. Os pais não tinham com quem deixar os filhos e nem quem cuidasse deles. Então levavam os filhos para a roça, desta maneira, ficavam tranquilos sabendo que seus filhos estavam bem.

Atualmente, não é mais permitido em virtude do Código de Conduta para a Comunidade do Café - 4C e do Estatuto da Criança e do Adolescente - ECA. O 4C é constituído por 10 práticas inaceitáveis. Estas práticas são: piores formas de trabalho infantil; trabalho escravo ou forçado; tráfico de pessoas; proibição de filiação ou representação por um sindicato; despejo forçado sem compensação adequada; não fornecimento de moradia adequada onde forem necessárias para os trabalhadores de classe; corte de floresta primária ou destruição de outras formas de recursos naturais; utilização de agrotóxicos proibidos e relações imorais nos negócios, conforme acordos internacionais, leis e práticas nacionais (CÓDIGO DE CONDUTA, 4C). 
O ECA dispõe sobre a proteção integral das crianças e dos adolescentes, assegurando-lhes a proteção integral que se traduz em todas as oportunidades e facilidades a fim de lhes facultar o desenvolvimento físico, mental, moral espiritual e social, em condições de liberdade e de dignidade, garantindo que todas as crianças e adolescentes sejam tratadas como pessoas que precisam de atenção, proteção e cuidados especiais para desenvolverem e serem adultos saudáveis (BRASIL, 1990).

Para as mulheres que trabalhavam ou trabalham fora, os maridos aceitavam ou aceitam, pois, segundo elas, é uma renda a mais que entra na casa. Dessa maneira, elas ajudam nas despesas da casa e têm suas próprias economias.

Algumas transformações na estrutura familiar mostra, o crescimento do desemprego dos chefes de família, o que induz mais mulheres, em particular as casadas e com filhos, a ingressar na força de trabalho buscando complementar o orçamento familiar (DAMASCENO, 2010). A inserção das mulheres no mercado de trabalho brasileiro, segundo Bruschini e Puppin (2004) tem sido caracterizada através do tempo pela marca da precariedade, o que atinge importante parcela das trabalhadoras.

Porém, em relação a ajudar nos serviços domésticos, a maioria das entrevistadas afirmou que tanto o marido quanto os filhos ajudavam ou ajudam. No entanto, algumas informaram que apenas os filhos ajudavam, outras somente $o$ marido, como: "Quando viajava meu marido cuidava dos filhos". (AGRICULTORA SANTO ANTÔNIO I).

Outras informaram que às vezes, como: "[...] varre terreiro, [...] põe arroz no fogo". (AGRICULTORA - BOA VISTA).

Três delas mencionaram que o companheiro ajuda a bagunçar.

Estudo realizado por Fernandes (2008), ao perguntar se o companheiro ajuda nas atividades domésticas, elas mencionaram que o esposo ou companheiro não tem participação efetiva na elaboração das tarefas domésticas e das refeições, exceto em finais de semana, quando participam de parte da elaboração da "comida" como uma forma de lazer. Eles cortam e assam a carne ou peixe na cozinha ou no quintal e ajudam a lavar a louça num clima festivo.

Ainda segundo a mesma autora, as mulheres relataram que os maridos encaram as tarefas domésticas como serviços fáceis e pouco cansativos, pelo fato de que quando resolvem participar das tarefas, o fazem como um "passatempo". Eles também acham que, pelo o fato de elas realizarem essas tarefas no espaço doméstico, elas têm a possibilidade de descansar, sentando de vez em quando para conversar com os filhos ou outras pessoas que estiverem na casa, o que não é possível fazer na roça.

Para Stropasolas (2006), ser agricultora não se restringe a exercer uma profissão na agricultura, mas exige que se leve em conta outros parâmetros que interferem sobre a representação que as agricultoras constroem delas mesmas, pois ser agricultora é também ser esposa, mãe, mulher e rural.

Corroborando Damasceno (2010), ao mencionar a participação feminina no mercado de trabalho, que cresceu significativamente nas últimas décadas, as mulheres estão presentes em todos os segmentos e classes empresariais, apesar de ainda existirem desigualdades de oportunidades no mundo do trabalho, diferenciais de rendimentos entre os dois sexo e obstáculos aos planos de ascensão a cargos de 
chefia, pois inúmeras vezes o trabalho feminino foi considerado como ajuda ou complemento ao trabalho masculino.

As mulheres, apesar da correria, conseguem conciliar as atividades domésticas com atuação em diferentes setores da cafeicultura e muitas gostam de trabalhar para ter seu próprio dinheiro, ajudar em casa e porque se sentem bem.

Houve relatos de algumas que passaram fome, necessidades financeiras, como agricultoras da região do Sossego e Boa Vista, mesmo assim, não desistiram de trabalhar no campo e mudar para a cidade. Conseguiram educar seus filhos e algumas estão educando os netos, como a agricultora da região do Coqueiro.

\subsection{Trajetória do trabalho fora de casa}

Das entrevistadas, onze (44\%) nunca trabalharam fora, somente na roça, desde pequenas, quatro (16\%) trabalharam no comércio, cinco $(20 \%)$ em casa de família, três (12\%), como merendeiras, uma (4\%), como professora e uma (4\%), como agente de saúde (Figura 2). Quem influenciou foram os pais, irmãos e a necessidade de sustento.

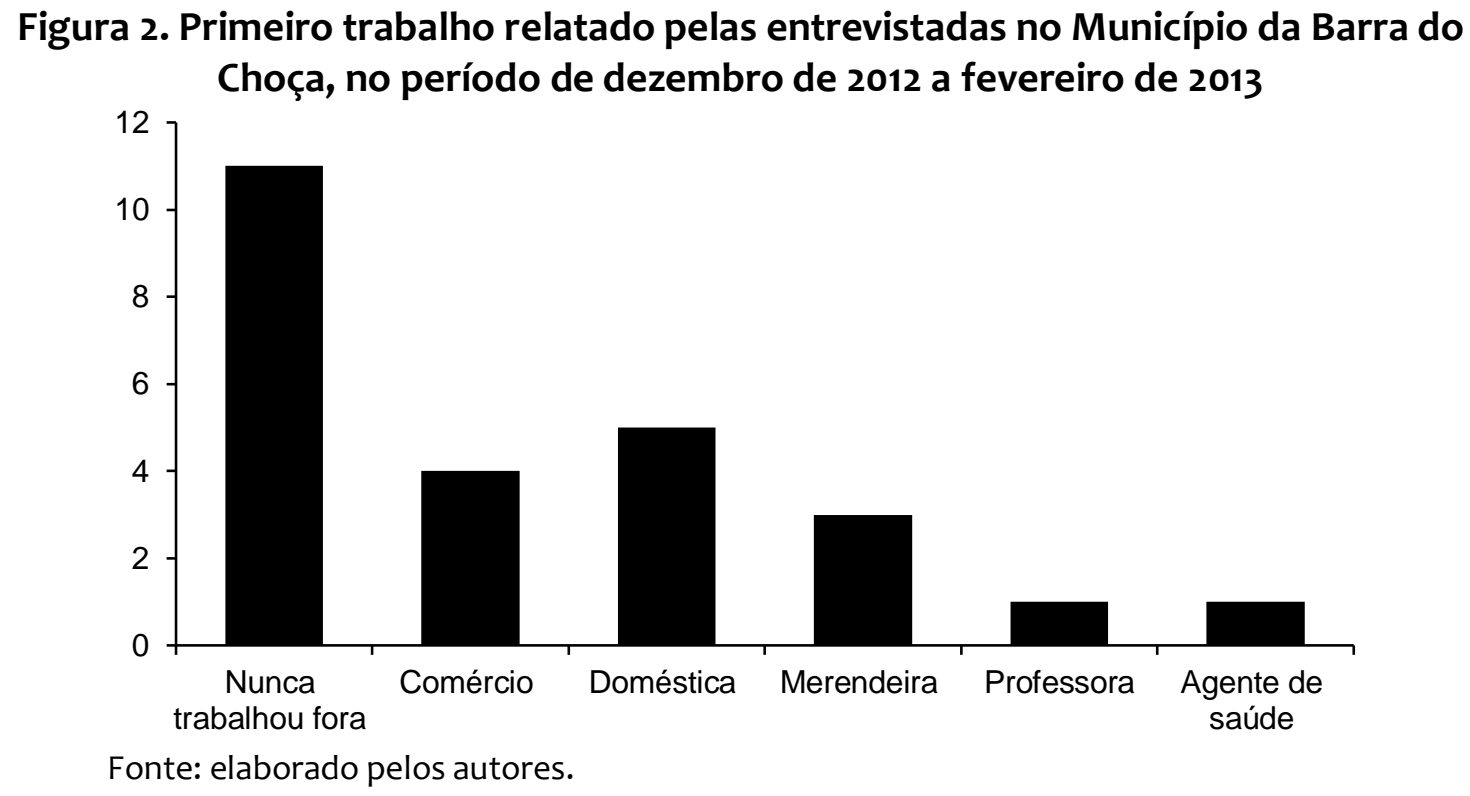

Sobre as dificuldades encontradas no dia a dia no setor da cafeicultura, as respostas foram: sol, ausência de chuva, ladeira (no local onde está plantado o café), frio e chuva (na época da colheita do café), preços dos insumos, colheita e beneficiamento do café, aplicação de produtos químicos, pagar alguém para cuidar do café, falta de mão de obra, manter a lavoura conservada, colher café do chão, conhecimento, falta de estufa e nenhuma.

Segundo Bernardes e Marcondes (2004), as principais dificuldades que influenciam na participação da mulher no mercado de trabalho são: dificuldades financeiras; de tempo, tendo em vista a busca do equilíbrio entre trabalho e família, principalmente relacionado à criação dos filhos; ansiedade, devido a uma economia não estável, concorrentes, fornecedores, clientes, processos trabalhistas são alguns 
fatores que deixam os empresários tensos e afetam suas relações familiares; separações e divórcios.

Das 25 entrevistadas, seis relataram que o fato de ser mulher interfere na atividade que desempenha. Para 18 entrevistadas, o fato de ser mulher facilita na atividade que desenvolve, pois "...mulher cata mais café que o homem”, “... mulher tem dinheiro". E quatro mulheres responderam que não facilita, pois "ainda existe preconceito", “... mulher e homem na mesma atividade”. Para a agricultora de Sossego: "Ainda há um pouco de preconceito, embora tenha uma presidente representando o Brasil". E as demais responderam que depende do lugar e da atividade.

Todas se sentem realizadas no trabalho que desempenham com o café. Entretanto, cinco das entrevistadas discordam que a mulher, hoje, possui condições de igualdade com os homens para trabalhar fora de casa. Elas mencionaram que ainda existe diferença, embora tenha melhorado muito a participação das mulheres no trabalho fora de casa, xontrapondo com 20 entrevistadas que mencionaram haver condições de igualdade entre homens e mulheres para trabalhar fora, por exemplo: "Mulher trabalha melhor que o homem. Mulher explica melhor que o homem, [...] quando chega na sociedade para conversar... Depois que a mulher começou a trabalhar na sociedade tudo começou a melhorar". (AGRICULTORA COQUEIRO). "Sim, pois a mulher agora tem vez de trabalhar, sim. Direito igual aos homens". (AGRICULTORA - MPA). "Com certeza, tem mulher que trabalha até mais que os homens" (Agricultora - SANTO ANTÔNIO II).

Isso nos retorna a discussão sobre gênero, pois muitos se referem a gênero como sinônimo de mulheres. Para Boni (2011), essa confusão é muito comum, mas as relações de gênero se constroem com homens e mulheres, afetando toda a sociedade. Segundo o mesmo autor, a compreensão das desigualdades de gênero e suas consequências são imprescindíveis para eliminarmos desigualdades, principalmente no meio rural, por exemplo, o que ocorre com os proprietários de lavoura cafeeira, ao contratarem mulheres para colher café no período da colheita, conforme foi mencionada por uma das entrevistadas: "[...] tem homem que não gosta de pegar café". (AGRICULTORA- SOSSEGO).

Mas, trabalhando e lutando pela sua independência, a mulher mostrou que é capaz de exercer vários papéis, garantindo assim maior participação na sociedade (TEIXEIRA, 2012). Para Rohnelt e Salamoni (2010), as mudanças e transformaçõos ocorridas no espaço rural nas últimas décadas provocaram um rearranjo nas unidades produtivas de base familiar, assim como na vida das pessoas que se organizam nesse espaço.

\subsection{Realização profissional}

Sobre o que consideram mais importante em sua vida, a maioria das entrevistadas respondeu que era a família, em especial os filhos. Entretanto, a agricultora da região do Pau Brasil mencionou o marido: "Meu esposo, pois para ter os meus filhos foi necessário ter esposo" (AGRICULTORA - PAU BRASIL)

Em seguida, responderam que era amar a Deus, ter saúde, amar ao próximo, trabalhar, agradecer a Deus, e diferenciando das respostas anteriores: 
"O que considero mais importante na minha vida é o de eu ser mulher" (AGRICULTORA - SOSSEGO)

Com essa resposta, fica evidente que, apesar das dificuldades encontradas no cotidiano, elas se valorizam, possuindo autoestima elevada e, desta maneira, sentindo-se capazes de mudar ou melhorar de vida.

Ao perguntar se sentiam-se capazes de agir e tomar decisões por conta própria, as respostas foram divididas, pois 12 afirmaram que sim, 11 consultam a família e duas responderam que às vezes, pois depende da situação. Essa resposta nos remete à mudança de comportamento das mulheres, pois, com o passar dos anos, as mulheres têm se destacado cada vez mais em diversos setores, adquirindo autonomia e segurança para resolver situações, até antes solucionada pelos homens. Outras, por comodidade, criação dos pais, ainda se sentem inseguras.

Em relação ao que deveriam fazer para aumentar o desempenho na atividade que exercem, as respostas foram bem diferentes (Figura 3).

Figura 3. Respostas das entrevistadas sobre o que deveria ser feito para aumentar a atividade que exercem

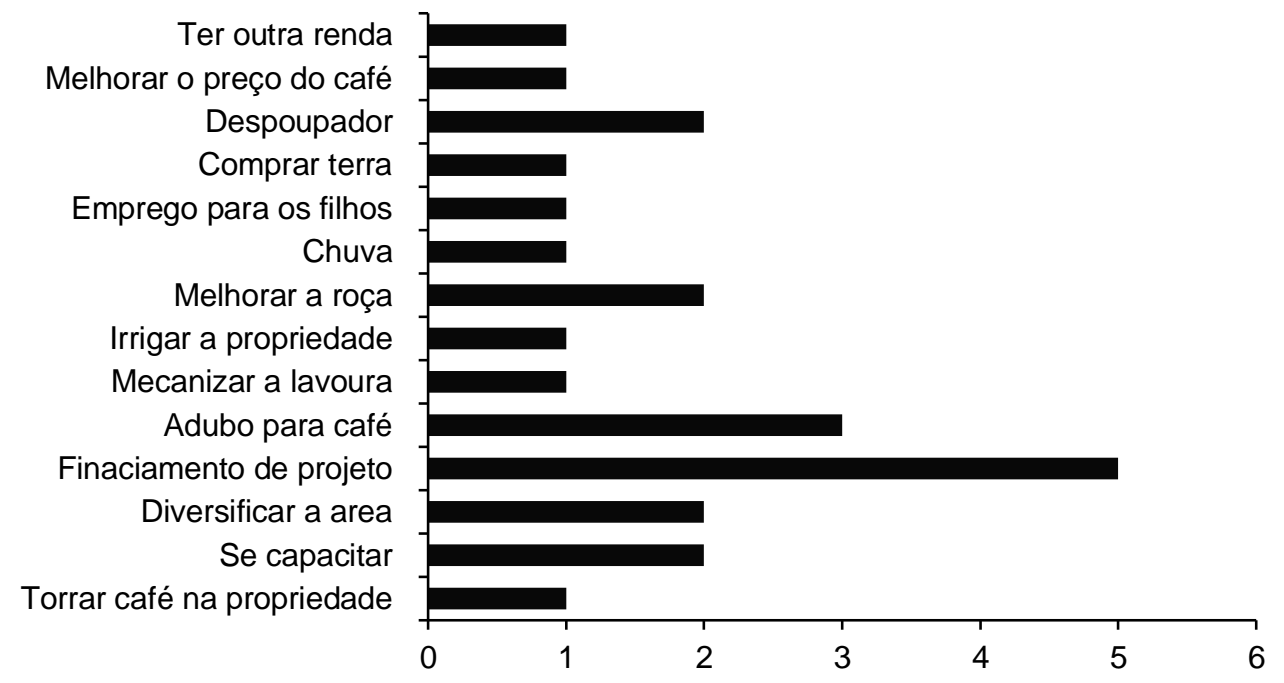

Fonte: elaborado pelos autores.

Dentre as respostas mencionadas pelas entrevistadas, cinco delas responderam que era a necessidade de financiamento, em seguida foi adubo para café, pois alegaram que os preços dos adubos estão muito elevados e elas não têm condições de comprá-los. Posteriormente, mencionaram a necessidade de capacitação, como concluir um curso superior; diversificar a propriedade, pois além do café, plantar milho e feijão e criar gado; mecanizar a lavoura, melhorar a roça e adquirir um despolpador melhor. Por fim, foi mencionado uma vez a torra de café na própria propriedade, necessidade de água para irrigar o café; ver os filhos empregados, pois têm família para sustentar; comprar mais terra e melhoria do preço do café.

E se sentiam realizadas profissionalmente, apenas uma mencionou que ainda não "Ainda não, pois preciso terminar os estudos. E na agricultura quero fazer mais" (AGRICULTORA - SOSSEGO). 
Como alternativa de melhoria e de aumentar a autoestima das mulheres que trabalham na cafeicultura, tem a IWCA, que tem como objetivo estimular e reconhecer a sua participação destas em todas as etapas da cadeia produtiva do café, desde o grão à xícara, e valorizar as mulheres nos países produtores.

\subsection{Lazer e finais de semana}

Sobre sair com as amigas, onze disseram que saem, vão à igreja, aniversários e tomam banho de rio. Ao perguntar o que é feito nos finais de semana e feriados com a família, nove responderam que ficam em casa, pois são os filhos e netos que vão à casa delas, onze mencionaram que visitam parentes e vizinhos, outras que almoçam fora e esporadicamente vão a eventos sociais, viajam, tomam banho de rio, vão à feira fazer compras. E das 25 entrevistadas, oito relataram que vão à igreja.

Estudos realizados por Neves e Medeiros (2013), ao analisar expressão de relações familiares e de gênero, foi mencionado pelas entrevistadas que o domingo é o dia de não trabalhar, de descansar, de ir ao culto, de receber e de visitar amigos e parentes. E por Fernandes (2008), ao estudar gênero e políticas de crédito, as mulheres mencionaram que o lazer era ir à missa e à casa das vizinhas.

Quando não estão trabalhando, as entrevistadas mencionaram que descansam em casa, leem a Bíblia e costuram (cinco), assistem televisão (quatro), vão à casa da vizinha, leem livro (duas), pintam e bordam, monta a cavalo, visitam as amigas, acessam a internet e dormem (uma), contudo três mencionaram que sempre estão trabalhando. Porém, elas não fazem somente uma atividade, ou seja, as que assistem televisão, também vão à casa das vizinhas. Uma deles informou que lê livros e também acessa a internet.

Estudo realizado por Cruz (2006), entrevistou 50 mulheres de duas cooperativas, 43 delas assistem televisão, duas dormem e descansam, três visitam amigos e parentes e duas vão ao shopping e cinema. Ressaltando que tanto neste estudo quanto no estudo realizado por Cruz (2006), as atividades tidas como descanso para as entrevistas são atividades domésticas.

\subsection{Mulher na cafeicultura}

A resposta para a primeira questão foi $100 \%$ sim, para as demais, a maioria respondeu que sim (Figura 4). 
Figura 4. Participação das mulheres na cadeia produtiva do café no município da Barra do Choça, no período de dezembro de 2012 a fevereiro de 2013

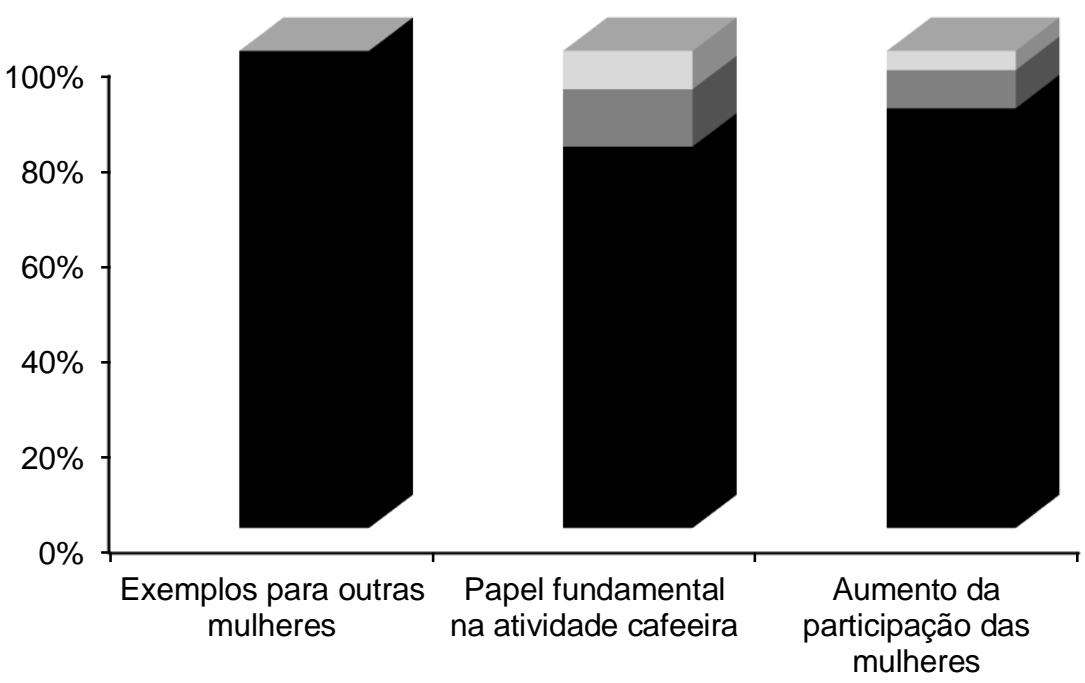

Não soube

- Não

- Sim

Fonte: elaborado pelos autores.

Para elas, as mulheres envolvidas na cafeicultura são exemplos para outras a permanecerem ou se inserirem nos diversos setores da cadeia produtiva do café na região da Barra do Choça. Em relação às mulheres terem exercido um papel fundamental na manutenção das atividades na cadeia produtiva do café na região da Barra do Choça, vinte das entrevistadas afirmaram que sim e algumas explicaram: "Todo mundo gosta de panhá café" (AGRICULTORA - INGAZEIRA). "Aqui tem mulher que a chuva pode tá caindo...tem coragem mesmo" (AGRICULTORA - SOSSEGO). "Tem algumas que são proprietárias. O plantio de café delas é separado. E algumas participam de concurso" (AGRICULTORA - BOA VISTA).

Esses relatos demonstram que, mesmo em condições adversas, as mulheres continuam realizando atividades dentro da cadeia produtiva do café. Esse fato foi confirmado quando se perguntou sobre o aumento da participação da mulher na atividade cafeeira, pois 22 informaram que sim, por exemplo: "Pois tem tanta mulher nas roças de café, sorrindo, cantando, alegre e brincando". (AGRICULTORA SOSSEGO). "Tem aumentado, depois do PRONAF Mulher". (AGRICULTORA COQUEIRO).

O Programa Nacional de Fortalecimento da Agricultura Familiar - PRONAF Mulher atende às propostas independentemente da condição civil da produtora agrícola, sendo uma medida que inclui as mulheres a acesso aos recursos, sejam eles de crédito produtivo, de terra ou de sucessão na área rural (REVISTA GLOBO RURAL on line, 2012).

Entretanto, uma não soube responder e duas mencionaram que não, como exemplo a agricultora da região Pau Brasil, alegando que, com a bolsa família, muitas mulheres não estão trabalhando mais: "Diminuiu por causa do governo Lula, [...] por causa da bolsa família”. (AGRICULTORA - PAU BRASIL).

Quando a agricultora fez este comentário ela estava se referindo a mulheres que deixam de trabalhar para ficar em casa cuidando dos filhos. Contudo, a bolsa família tem ajudado muitas famílias que antes viviam na pobreza e extrema pobreza, reduzindo a fome e a miséria. 
As entrevistadas fazem parte de Cooperativas e de movimentos sociais, sendo que nove são cooperadas da Cooperbac, uma da Cooperativa Mista Agropecuária Conquistense Ltda - Coopmac, uma da Coopasub, uma da União das Cooperativas de Agricultura Familiar e Economia Solidária - Unicafes, três do MST e do MPA. A Cooperbac e Coopmac são cooperativas que trabalham com café, cuja sede é na Barra do Choça e Vitória da Conquista, respectivamente. A COOPERBAC, além do café, comercializa outros produtos, como banana e mandioca, que são vendidos para o Programa Nacional de Alimentação Escolar - PNAE.

A Cooperbac tem grande importância para essas produtoras, pois, depois de inserirem nesta cooperativa, a qualidade de vida melhorou, porque antes seus produtos eram vendidos pelos atravessadores com o preço abaixo do mercado e, atualmente, o café e os outros produtos são vendidos para a cooperativa e PNAE.

Nodari e García (2012), ao estudarem o papel desempenhado pelas mulheres no sistema cooperativo, concluíram que elas participam ativamente da cooperativa, seja na diretoria, no planejamento ou nas execuções das ações. É o que pode ser observado pelas cooperadas da Cooperbac, que participam de reuniões, fazem parte da diretoria e discutem sobre a melhoria da cooperativa.

Recentemente, os representantes da Cooperbac estiveram reunidos com o secretário estadual da Agricultura para discutir a implantação da indústria de beneficiamento do café no município, pois conforme esclareceu a diretora da Cooperbac:

a cooperativa já produz café de qualidade, com o selo da agricultura familiar, mas ainda terceiriza a torrefação e moagem do grão. Com a criação da agroindústria na região temos a condição de produzir e comercializar um café inteiramente fabricado por nós", (SEAGRI, 2013).

A implementação da agroindústria de café no município irá gerar emprego, renda e melhoria na qualidade de vida das mulheres que contribuem para o setor cafeeiro.

\subsection{Quem é a entrevistada?}

O item "Quem a entrevistada?" sugere a definição da própria mulher sobre ela mesma, ou seja, uma apresentação sobre ela mesma. "Sou eu”, ...é eu”, foram às respostas mais escutadas, ao perguntar quem era o nome da entrevistada. Entretanto, houve outras respostas, como: "Sou eu... Aquela que enfrenta a batalha, vai à luta e não desiste." (AGRICULTORA - COQUEIRO). "Eu, euzinha aqui, oh! Calma, alegre. Todo mundo gosta 'deu'." (AGRICULTORA - INGAZEIRA). Sou eu... branca, bonita, cabelo branco (AGRICULTORA - SANTO ANTÔNIO II). "Bonita, elegante, solteira, novinha, tô começando a vida agora. Sou apaixonada por criança e pássaro." (AGRICULTORA - INGAZEIRA). "É eu. Tem que valorizar a gente... E quem tem que gostar de mim sou eu mesma." (AGRICULTORA - SOSSEGO). "É eu, sou eu mesma... Paciente, muito guerreira. Que tem esperança. E com fé em Deus a gente vence... Gosto de incentivar as pessoas." (AGRICULTORA - INGAZEIRA). "Uma aventureira. Uma doida que não tem juízo" (AGRICULTORA - ASSENTAMENTO MOCAMBO). "Uma pessoa apaixonada pelo trabalho, de mãos dadas com a família, [...] acreditando em Deus, acima de tudo.” (AGRICULTORA - SOSSEGO). 
Com estas respostas foi possível perceber que essas mulheres possuem autoestima elevada, reconhecem seu valor. E por mais que a vida foi ou esteja difícil, nunca desistem de enfrentar os obstáculos.

\section{CONCLUSÃO}

Percebeu-se que, após algumas entrevistas, as mulheres ficaram pensativas e algumas falaram "é só isso?", após o término da entrevista.

Atualmente, a situação cafeeira está em crise, principalmente em decorrência da seca na região e, apesar das dificuldades, elas querem permanecer com a lavoura de café, pois, devido a esta cultura, conseguiram melhorar sua qualidade de vida.

As mulheres envolvidas na cafeicultura são exemplos para outras mulheres a permanecerem ou se inserirem nos diversos setores da cadeia produtiva do café na região da Barra do Choça.

A participação tem aumentado em todos os setores da cadeia produtiva, principalmente em participação nas cooperativas.

Essas mulheres possuem autoestima elevada, pois estão satisfeitas com sua vida, que inclui trabalho em diferentes setores do café, família, têm seu próprio dinheiro investir em novas atividades ou para uso pessoal.

\section{REFERÊNCIAS}

BERNARDES, C.; MARCONDES, R. C. Criando empresas para o sucesso:

empreendedorismo na prática. São Paulo: Saraiva, 2004.

BONI, V. Gênero: o doméstico e o produtivo na agroindústria familiar. Disponível em: www.alasru.org/wp-content/uploads/2011/06/01-GT-Valdete-Boni.doc. Acesso em: 27 ago. 2015.

BRASIL. Estatuto da Criança e do Adolescente, Câmera dos Deputados, Lei n. 8.069, de 13 de julho de 1990. DOU de 16/07/1990 - ECA. Brasília, DF. Disponível em: http://www.planalto.gov.br/ccivil_03/leis/18069.htm. Acesso em: 27 ago. 2015.

BRUSCHINI, C.; LOMBARDI, M. R.; UNBEHAUM, S. Trabalho, Renda, Políticas Sociais: avanços e desafios. In: BARSTED, L. L.; PITANGUY, J. O Progresso das Mulheres no Brasil 2003-2010. Rio de Janeiro: CEPIA; Brasília: ONU Mulheres, 2011.

BRUSCHINI, C; PUPPIN, A. B. Trabalho de Mulheres Executivas no Brasil no final do século XX. Cadernos de Pesquisa, v. 34, n. 121, p. 105-138, jan./abr. 2004.

CASTILHO, C. B. de.; SCHNEIDER, S. Gênero, trabalho rural e pluriatividade. In SCOTT, P.; CORDEIRO, R.; MENEZES, M. Gênero e geração em Contextos Rurais. 2010. Ilha de Santa Catarina: Mulheres, 2010. 
CIRILO, B. Mulheres lideram cooperativas e sindicatos rurais. Disponível em: <http://www.dci.com.br/agronegocios/mulheres-lideram-cooperativas-e-sindicatosrurais-id335551.html.>. Acesso em: 25 out. 2013.

CIROLINI, V.; NORO, G. B. A participação da mulher na gestão das cooperativas: Um estudo realizado na Cotrisel. Disciplinarum Scientia, Série: Ciências Sociais Aplicadas, v. 4, n. 1, p. 29-43. 2008.

CODIGO DE CONDUTA. Disponível em: http://www.4ccoffeeassociation.org/uploads/media/4C_Code-ofConduct_IllustratedGuide_pt.pdf?PHPSESSID=9edcsuk5rqnne8e85lk95V1cn3. Acesso em: 26 ago. 2015.

CRUZ, T. C. da S. "Qual é o teu trabalho, mulher?" Mulheres empreendedoras no contexto da Economia Popular Solidária. Tese (Doutorado em Sociologia) Programa de Pós Graduação em Sociologia, Universidade de Brasília. 2006. Disponível em: www.scielo.br/pdf/se/v21n2/a16v21n2.pdf. Acesso em: 29 ago. 2013.

DALLER, V. L. O. Estratégia do Desenvolvimento do Cooperativismo e Associativismo,. In: Brasil. Ministério da Agricultura, Pecuária e Abastecimento. Cooperativismo de gênero / Ministério da Agricultura, Pecuária e Abastecimento. Secretaria de Desenvolvimento Agropecuário e Cooperativismo. Brasília : Mapa/ACS, 2009.

DAMASCENO, L. D. J. Empreendedorismo Feminino: Um estudo das mulheres empreendedoras com modelo proposto por Dornelas. Monografia (Bacharel em Administração) - Graduação em Administração de Empresas, Faculdade Sete de Setembro, 2010. Disponível em: tupi.fisica.ufmg.br/...mulher.../017\%20\%20Empreendedorismo\%2ofeminino.pdf. Acesso em: 27 out. 2013.

EBDA. Cadeia produtiva do café está presente na Fenagro. Disponível em: http://www.ebda.ba.gov.br/cadeia-produtiva-do-cafe-esta-presente-na-fenagro2012. Acesso em: 20 ago. 2013.

FERNANDES, S. A. Gênero e políticas de crédito: 0 Pronaf Mulher em Santa Catarina. Dissertação (Mestrado em Sociologia Política) - Programa de Pós Graduação em Sociologia Política, Universidade Federal de Santa Catarina, 2008. Disponível em: https://repositorio.ufsc.br/handle/123456789/91928. Acesso em: 25 out. 2013.

GOHN, M. G. Movimentos Sociais no inicio do século XXI - Antigos e novos atores sociais. Petrópolis, RJ: Vozes, 2003.

GOHN, M. G. Mulheres - atrizes dos movimentos sociais: relações políticos-culturais e debate teórico no processo democrático. Política e Sociedade, Florianópolis, v.6, n.11, p. 41-70. 2007. 
GOMES, A. F. Ação empreendedora e relação de gênero: Um estudo multicasos na cidade de Vitória da Conquista, Bahia. Tese (Doutorado em Administração) Programa de Pós Graduação em Administração, Universidade Federal de Lavras, 2010. Disponível em:

repositorio.ufla.br/.../TESE_Ação\%20empreendedora\%20e\%20relações\%20de\%2ogêne . Acesso em: 29 out.2013.

JONATHAN, E. G. Mulheres empreendedoras: medos, conquistas e qualidade de vida. Psicologia em Estudo, v. 10, n. 3, p. 373-382, set./dez. 2005.

LOMBARDI, R. M. A ocupação no setor agropecuário no período 1993-2006 e o trabalho das mulheres. Disponível em:

http://portal.mda.gov.br/portal/nead/arquivos/view/textos-digitais/Artigo/artigos2009/Artigo_008.pdf. Acesso em: 22 ago. 2015.

LOVATTO, P. B.; CRUZ, P. P.; MAUCH, C. R.; BEZERRA, A. A. Gênero, sustentabilidade e desenvolvimento: uma análise sobre o papel da mulher na agricultura familiar de base o papel da mulher na agricultura familiar de base ecológica. Redes, v. 15, n. 2, p. 191 - 212, mai./ago. 2010.

MORAIS, E. E.; LANZA, F.; SANTOS, L. M. L. dos; PELANDA, S. S. Propriedades coletivas, cooperativismo e economia solidária no Brasil. Serviço Social e Sociedade, n. 105, p. 67-88, jan./mar. 2011.

NAZZARI, K.; BERTOLINI, G.F.; BRANDALISE, L. T. Gestão das unidades artesanais na agricultura familiar: Uma experiência no Oeste do Paraná. In: Cascavel : UNIOESTE, 2007, 163 p.

NETO, A. S. Mulheres do Café. Disponível em: http://www.cafepoint.com.br/cadeiaprodutiva/mulheres-do-cafe. Acesso em: 20 out. 2015.

NEVES, D. P.; MEDEIROS, L. S. Mulheres camponesas: trabalho produtivo e engajamentos políticos. Niterói: Alternativa, 2013.

NODARI, T. M. S.; GARCÍA, R. M. O papel desempenhado pelas mulheres no sistema cooperativo: Um estudo em Assentamento de Campos Novos - SC. Revista de Administração Contabilidade e Economia, v. 11, n. 1, p. 27-52, jan./jun. 2012.

PEDRO, J.M. Traduzindo o Debate: O Uso da Categoria Gênero na Pesquisa Histórica. Revista História, São Paulo, v.24, n.1, p.77-98. 2005.

PEREIRA, J. S.; SOUZA, S. E. de; SANTOS, P. R P.; AFONSO JUNIOR, P. C.; COSTA, H. A.; TRINDADE, P. B.; TRINDADE, P. B. Cafés Sustentáveis, avaliação do grau de conformidade da cafeicultura familiar em Barra do Choça - BA, sobre as exigências da produção integrada. In: VII Simpósio de Pesquisa dos Cafés do Brasil, Araxá MG, 2011. 
REVISTA GLOBO RURAL online. Pronaf Mulher aumenta limite de crédito para trabalhadora rural. Disponível em:

http://revistagloborural.globo.com/Revista/Common. Acesso em: 29 ago.2013.

RIBEIRO, P. S. O papel da mulher na sociedade. Disponível em:

http://www.brasilescola.com/sociologia/o-papel-mulher-na-sociedade.htm. Acesso em: 25 ago.2015.

RÖHNELT, P.B.C.; SALAMONI, G. O papel da mulher nas transformações da agricultura familiar: A pluriatividade como estratégia de reprodução social. In: Anais... XVI Encontro Nacional dos Geógrafos, Porto alegre - RS, 2010.

SANTOS, G. I. R. de. Desenvolvimento Regional sob o Enfoque de Gênero: Assentamento de Reforma Agrária Padre Joio I e II - TO. Dissertação (Mestrado em Desenvolvimento Regional e Agronegócio) - Programa de Pós Graduação em Desenvolvimento Regional e Agronegócio, Universidade Federal do Tocantins. 2009 .

SEAGRI. Secretário e COOPERBAC discutem projeto de construção de agroindústria de café em Barra do Choça. Disponível em: http://www.seagri.ba.gov.br/noticias.asp?qact=view\&notid=27949. Acesso em: 29 ago. 2013.

SCHEMER, M. L. T.; CARVALHO, G. M. Empreendedorismo e estratégia de empresas de pequeno porte 3Es2Ps: Coleção Empreendedorismo e Estratégia, 1. Curitiba: Champagnat, 2010.

STROPASOLAS, V. L. O Mundo Rural no Horizonte dos Jovens. Florianópolis: Editora da UFSC, 2006.

TEIXEIRA, M. da S. Perfil da Mulher no Mercado de Trabalho. Revista de Psicologia, v.1, n.17, p. 95-123, jul. 2012.

Paulo Roberto Pinto Santos. Doutor em Desenvolvimento Regional e Atualmente é Reitor da UESB e docente da disciplina do café na Universidade Estadual do Sudoeste da Bahia (UESB) Campus de Vitória da Conquista. psantosautomatic@gmail.com

Ariana Lisboa Meira. Doutora em Agronomia área de concentração Fitotecnia. Atualmente docente do Instituto de Formação em Barra da Estiva, BA. arilismeira@yahoo.com.br

Sandra Elizabeth Souza. Professora titular do Departamento de Fitotecnia e Zootecnia da Universidade Estadual do Sudoeste da Bahia. Responsável pelas disciplinas Fitopatologia I e Cultura do Café. elizauesb@hotmail.com 